TM- 1012

1620.000

CCI Report No. 390-124

VACUUM BREAKS OF THE DOUBLER MAGNET SYSTEM
PREPARED UNDER FERMILAB SUBCONTRACT NO. 94199 BY CRYOGENIC CONSULTANTS, INC.
ALLENTOWN, PA.

FOR

FERMI NATIONAL ACCELERATOR LABORATORY

BATAVIA, ILLINOIS

October 31,1980 
Section

INTRODUCT ION

CASE I - RUPTURE OF A PUMPOUT CONNECTION OF THE COLD BEAM TUBE VACUUM SYSTEM

CASE II - BREAK OF A PUMP LINE TO THE INSULATING VACUUM OF THE MAGNET STRING

RECOMMENDAT IONS

REFERENCES
11

Page No.

2

2

8

12 


\section{VACUUM BREAKS OF THE DOUBLER MAGNET SYSTEM}

\section{INTRODUCTION:}

The energy doubler system contains two vacuum systems; the cold beam tube vacuum and the insulating vacuum system. These two systems are independent of each other. Both have connections to the outside world through pumpouts. This report attempts to make an estimate of the effect of a massive failure (large rupture of a connection to the outside world) upon the magnets and the contained helium in the magnet system.

It is assumed that the event takes place with magnets full of helium, at steady state cryogenic conditions, but without magnetic field. Quenching of the magnets is therefore not a part of this analysis.

CASE I - RUPTURE OF A PUMPOUT CONNECTION OF THE COLD BEAM TUBE VACUUM SYSTEM:

Figures 5.1 and 5.2 (pp. 94 and 95) of the 1979 Design Report for the Superconducting Accelerator (ref. 1) show a pumpout connection and the general arrangement of system components, respectively. The cold beam tube is equipped with section gate valves at intervals of roughly 800 . $f t$. These valves close quickly (in less than 1 sec), and closure is interlocked with the Bayard-Alpert gauges.

It is postulated that one of the pumpout connections is destroyed and that it will present in the worst case a wide open connection to the atmosphere in the tunnel through an opening of 1-1/4 in. diameter to the cold beam tube. Velocity in the opening will at maximum be sonic, and pressure then will be approximately 380 Torr. The mass flow rate associated with this is approximately $120 \mathrm{~g} / \mathrm{sec}$. If the walls of the beam tube can liquefy or solidify the air at the rate at which it enters, pressure in the bore tube will then be 380 Torr or less.

In order to freeze $120 \mathrm{~g} / \mathrm{sec}$ of air, approximately 460 joules per gram of heat need to be removed (data are based on pure nitrogen, which is permissible within the accuracy of the estimate). Maximum heat flux to the bore tube is than of the order of $55,200 \mathrm{~W}$. The maximum heat flux obtainable through the wall of the bore tube is of the order of $1 \mathrm{~W} / \mathrm{cm}^{2}$. Reference 2 indicates a maximum heat flux in the nucleate boiling regime for liquid helium of approximately $1 \mathrm{~W} / \mathrm{cm}^{2}$. This occurs at a temperature difference of $1^{\circ} \mathrm{K}$. When this 


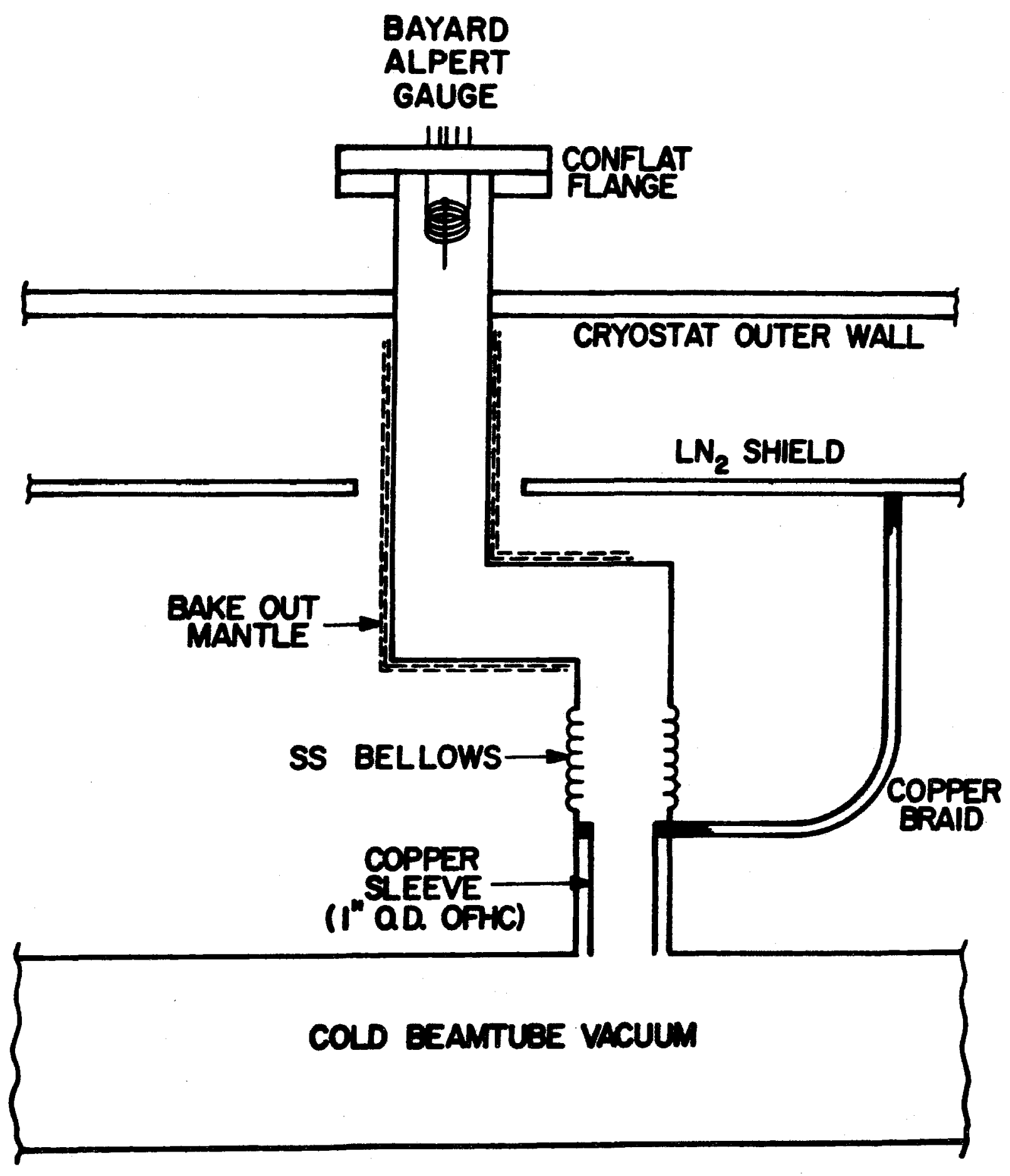

Fir. 5-1. Schematic of the "oniffer" port to the cold beamtube vacuum. 

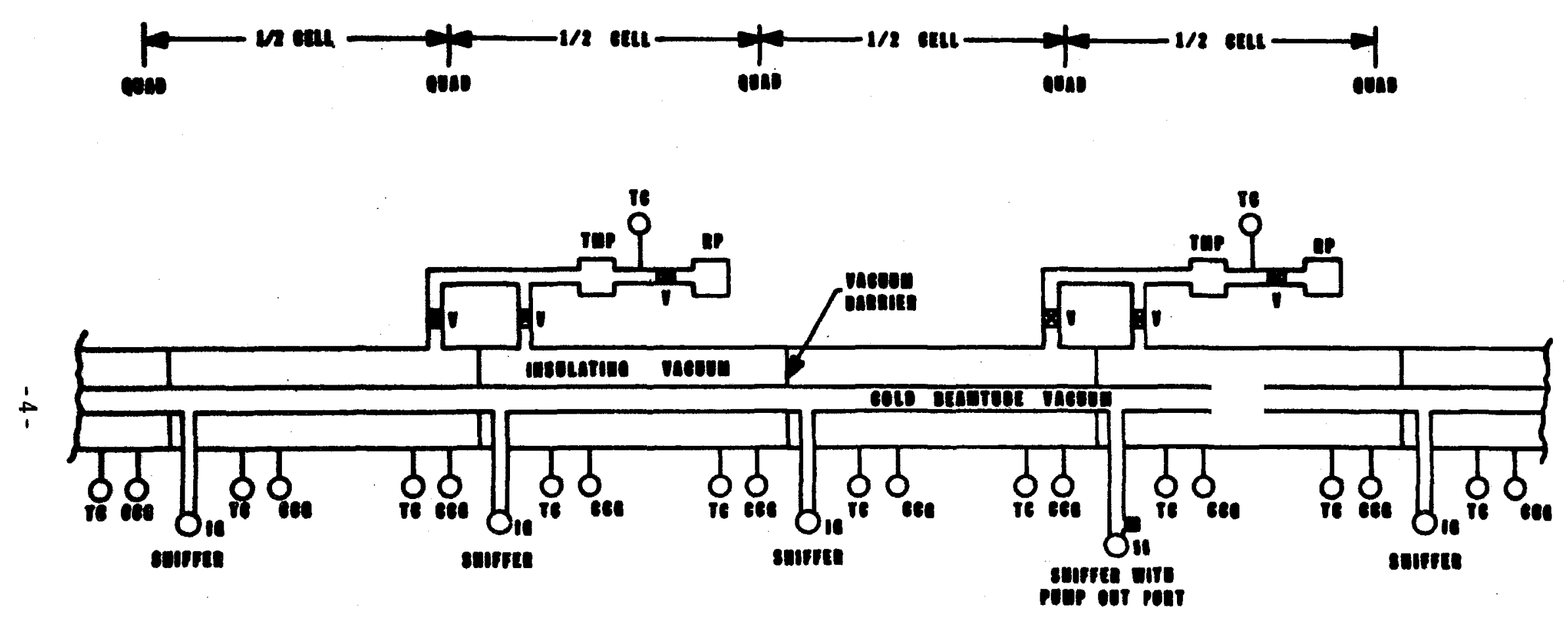

Fis. 5-2. Typical section of cold beamtube and insulating vacuum. 
temperature difference is exceeded, film boiling occurs with a much lower coefficient of heat transfer. The value of $1 \mathrm{~W} / \mathrm{cm}^{2}$ will not be exceeded until a temperature difference of $20-25^{\circ} \mathrm{K}$ is generated between wall and fluid (ref. 2).

Transfer of heat by condensation indicates a heat flux of $1 \mathrm{~W} / \mathrm{cm}^{2}$ at $\Delta T=5^{\circ} \mathrm{K}$ and $2 \mathrm{~W} / \mathrm{cm}^{2}$ at $\Delta \mathrm{T}=9^{\circ} \mathrm{K}$ (ref. 3). If the pressure in the bore tube is at $.5 \mathrm{~atm}$, then condensation of $\mathrm{N} 2$ takes place at a temperature of $72^{\circ} \mathrm{K}$. It appears that the maximum temperature difference between wall and helium may be of the order of $50-60^{\circ} \mathrm{K}$. Maximum heat flux through the wall is then of the order of $2 \mathrm{~W} / \mathrm{cm}^{2}$. To transfer $55,200 \mathrm{~W}$ of heat then requires a minimum of $27,600 \mathrm{~cm}^{2}$ of surface area. This represents approximately $40 \mathrm{ft}$ of bore tube. It appears that the bore tube provides sufficient surface to condense or freeze the in-flowing air at a rate to maintain a low pressure in the bore tube.

Pressure drop in the bore tube is low. This can be visualized by estimating the velocity of the air flowing in at the point where it has been cooled to a temperature of $80^{\circ}$ or less. At a pressure of $.5 \mathrm{~atm}$ and a temperature of $80^{\circ} \mathrm{K}$, specific volume of the gas is approximately $460 \mathrm{cc} / \mathrm{gr}$. The cross section for $f 10$ is of the order of $75 \mathrm{~cm}^{2}$ (both sides of the bore tube). The gas velocity then would be $750 \mathrm{~cm} / \mathrm{sec}$ or less. Obvious1y, it will be impossible to maintain a pressure of $.5 \mathrm{~atm}$. At the triple point pressure of $.12 \mathrm{~atm}$, the vapor velocity will be $\left(\right.$ at $80^{\circ} \mathrm{K}$ ) approximately $3,000 \mathrm{~cm} /$ sec. Since this is still a low velocity, it is to be expected that 1iquid formation will not occur in the bore tube and that only sublimation will take place.

The volume of solid generated is relatively small. It is some $140 \mathrm{cc} / \mathrm{sec}$ and, with the large amount of cold surface area participating in heat transfer, layer thickness growth will be of the order of .001 to .002 in. per sec, dependent on location in the bore tube. Right after the break occurs, air flow will not penetrate far into the bore tube on either side of the break. When gate valves in the bore tube close within $1 \mathrm{sec}$, air will not enter the closed-off sections. Because of the high rate of heat transfer, initially some $100 \mathrm{ft}$ of magnets next to the pumpout will receive the bulk of the $55 \mathrm{~kW}$.

The amount of single phase helium present in $100 \mathrm{ft}$ of dipoles is of the order of 100 liters or $12,500 \mathrm{gr}$. Approximately half of this is in intimate thermal contact with the bore tube. We will, therefore, assume that this helium only participates in the heat transfer during the initial seconds after the break occurs. Then rate of rise of internal energy of this liquid is 9.0 joules/g-sec. Since the liquid can expand into other regions of the single phase system, initial 
pressure will only rise to the extent required to displace the liquid. If we assume a local pressure of 2.5 atma (22 psig), volume increase with time will be as in Table I:

T A B L E I

\begin{tabular}{llcccc}
\hline $\begin{array}{l}\text { Time } \\
\text { Sec }\end{array}$ & $\begin{array}{c}\text { Temp. } \\
{ }_{\mathrm{K}}\end{array}$ & $\begin{array}{c}\text { Spec. Vol } \\
\text { cc/gr }\end{array}$ & $\begin{array}{c}\text { Pres } \\
\text { atm }\end{array}$ & $\begin{array}{c}\text { Internal } \\
\text { Energy-J/gr }\end{array}$ & $\begin{array}{c}\text { Enthalpy } \\
\mathrm{J} / \mathrm{gr}\end{array}$ \\
\hline$-0-$ & 4.5 & 8.11 & 1.8 & 9.72 & 11.2 \\
.16 & 4.8 & 9.13 & 1.8 & 11.96 & \\
.32 & 5.08 & 10.40 & 2.05 & 14.20 & \\
.48 & 5.21 & 12.90 & 2.3 & 16.44 &
\end{tabular}

The data of Table I are estimated by assuming a local pressure rise which, in turn, indicates specific volume and temperature of the local fluid. Essentially, the average heat input to a dipole is of the order of $15 \mathrm{~kW}$, and this rate of heating will determine the rate of venting from the magnet. This rate even holds at the entrance to the bore tube near the break. An estimate of a conventionally determined heat transfer coefficient shows that it is of the order of $5.7 \times 10^{-3} \mathrm{~W} / \mathrm{cm}^{2}{ }^{\circ} \mathrm{K}$, based on full flow rate at $200-300^{\circ} \mathrm{K}$ near the entrance of the bore tube. This coefficient together with $\Delta \mathrm{T}=200^{\circ} \mathrm{K}$ indicates rate of heat transfer of less than $1.14 \mathrm{~W} / \mathrm{cm}^{2}$.

A heat transfer rate of $15 \mathrm{~kW}$ into a dipole cryostat can be handled by the relief system of the single phase fluid channe1. It is a heat input considerably less than the heat input by the windings during a quench. The flow of air into the bore tube will only stop after all of the bore tube between closed gate valves will have been warmed to a temperature of the order of $80^{\circ} \mathrm{K}$. From this time on, pressure in the bore tube will be atmospheric, and liquid air will be present. With the insulating vacuum in tact, liquid air will not boil off, and there is no danger of a sudden high rate of vaporization of the accumulated liquid.

Condensation of air in the bore tube will proceed for a fairly long time. All of the mass of the magnets in a $400 \mathrm{ft}$ section will be warmed to $70-80^{\circ} \mathrm{K}$ by condensing air. If this mass is $20,000 \mathrm{1b}$, some $7 \times 107$ joules of heat are required. This is supplied by $1.5 \times 105 \mathrm{grams}$ of air. The volume of liquid will be of the order of 180-200 liters. 
Volume of the bore tube can accommodate this quantity. Time required to add this much air is at least $1,5.00 \mathrm{sec}$ with flow entering at a high rate and another 1,000 to $2,000 \mathrm{sec}$ with flow at decreasing rates.

Helium flowing out of the magnets into the collection header will cool this header rapidly. For instance, flow at a rate of 10 liters of liquid per sec (initial rate from 4 magnets) will cool the header at a rate of $1.5-2 \times 106 \mathrm{~W}$. This rate will not persist for 1 ong, because after the first 4 magnets have been emptied of helium, they still will be very cold and will provide massive cooling and condensing duty.

The header consists of 8 in. IPS, Schedule 5 stainless steel pipe. It weighs approximately $10 \mathrm{lb}$ per $\mathrm{ft}$ and 300,000 joules are required to cool $1 \mathrm{ft}$ of length from ambient temperature to $80^{\circ} \mathrm{K}$. If a total of 600 liters of helium is vented through the header, some $10^{8}$ joules of cooling are available. It appears that $300 \mathrm{ft}$ of 8 in. pipe can be cooled to $80^{\circ} \mathrm{K}$. More likely, some 400-500 are cooled of which 250-300 ft to $80^{\circ} \mathrm{K}$.

\section{Conclusions:}

1. Closure of gate valves of the afflicted section of bore tube will prevent air from entering adjacent bore tube sections.

2. Initially, air flowing into the bore tube will freeze out in the first 50 or so $f t$ of the bore tube on either side of the break.

3. Rate of heating of the helium system will be of the order of $15 \mathrm{~kW}$ per dipole.

4. All of the magnets in the afflicted section will ultimately be involved in the cryopumping process.

5. The high flow rate of air entering through the break will persist for a period of 15-20 min.

6. Magnets will be warmed to a temperature of some $80^{\circ} \mathrm{K}$ over a period of possibly as much as $1 \mathrm{hr}$. During this time, some 200 liters of liquid air will accumulate in the bore tube.

7. Helium flow through relief valves into the 8 in. header will occur over a period of 5-10 min. During this time, the bulk of the liquid in the single phase system will be driven out of the magnets. Pressure drop in the 8 in. header will be low. The header will become very cold over a length of 300-500 ft between magnet relief valve 
connections and master relief valve. Line construction needs to take into account thermal contraction.

8. Liquid air present in the bore tube will evaporate slowly, as long as the insulating vacuum of the magnets is maintained.

CASE II - BREAK OF A PUMP LINE TO THE INSULATING VACUUM OF THE MAGNET STRING:

The schematic arrangement of the pumpout system is shown in Figure 5.2. The pumpouts evacuate the insulating vacuum only and not the bore tube. It is postulated that at one location the pumpout assembly consisting of two valves is broken off, and air flows in through the holes into the vacuum space. Flow proceeeds on both sides of the liquid nitrogen cooled shield. Mass flow rate into the vacuum space in first instance is at sonic velocity through the $2-1 / 2$ in. opening. This determines the maximum flow rate.

The insulating vacuum can be separated into two parts; the volume outside the nitrogen shield is of the order of $12 \mathrm{cft}$ per $100 \mathrm{ft}$ of length; the volume inside the nitrogen shield is of the order of $1.4 \mathrm{cft}$ for $100 \mathrm{ft}$ of length. We may assume that the volume outside the nitrogen shield fills up quickly with air of a temperature somewhere between ambient and $80^{\circ} \mathrm{K}$. The pressure in this space is determined by the rate of leakage from this space to the space between nitrogen shield and the $2 \emptyset$ helium tube at the crossovers from magnet to magnet. The flow area of the $2-1 / 2$ in. $0 . D$. tube is of the order of $5 \mathrm{sq}$. in. The flow area into the space between nitrogen shield and $2 \emptyset$ helium tube is of the order of 2 sq. in.

Assume sonic velocity through the $2-1 / 2$ in. hole. This will give a flow rate of $270 \mathrm{~g} / \mathrm{sec}$ of air. This much air cannot be admitted to the space between nitrogen shield and $2 \emptyset$ helium for one magnet, since we would exceed sonic velocity. Assume that the rate of admittance is proportional to flow area times .5 to account for a further drop in pressure in order to get the velocity back up to sonic. Then mass flow rate per magnet for cryopumping is of the order of:

$$
\frac{2}{5} \times .5 \times 270=54 \mathrm{~g} / \mathrm{sec} \text {. }
$$

Cryopumping surface area is of the order of $24,000 \mathrm{~cm}^{2}$. At $1 \mathrm{~W} / \mathrm{cm}^{2}$ we can transmit $24 \mathrm{~kW}$ or freeze air at a rate of $52 \mathrm{~g} / \mathrm{sec}$. As a result of the high heat flux, the two phase helium system will eject its mass at a very high rate, and considerable warming will occur rapidly. This, in turn, will heat single phase liquid and start venting of this 
fluid. The rate of heat transfer to the single phase fluid will certainly be below the $15 \mathrm{~kW}$ calculated under Case $\mathrm{I}$, because of the barrier of helium gas in the two phase system.

Mass in the two phase helium system varies as a function of magnet location. The worst case is the end of the string of magnets where the two phase system contains 20 liters of liquid and 5 liters of gas. Time to reach a pressure of $4 \mathrm{~atm}$ is of the order of. $5 \mathrm{sec}$, as shown in Table II:

\section{T A B $\quad$ L E $\quad$ E I I}

$\begin{array}{rlrl}\mathrm{P} & =1.2 \mathrm{ata} & \mathrm{P} & =4 \text { ata } \\ \mathrm{M} & =2,600 \mathrm{gr} & \mathrm{M} & =2,600 \mathrm{gr} \\ \mathrm{V}_{\mathrm{S}} & =9.6 \mathrm{cc} / \mathrm{gr} & \mathrm{V}_{\mathrm{S}} & =9.6 \mathrm{cc} / \mathrm{gr} \\ \mathrm{I} & =26,877 \text { joules } & \mathrm{I} & =39,000 \mathrm{joules} \\ \mathrm{T} & =4.2^{\circ} \mathrm{K} & \mathrm{T} & =5.65^{\circ} \mathrm{K} \\ \Delta \mathrm{I} & =12,000 \text { joules } & \Delta \mathrm{Time} & =\frac{12000}{24000}=.5 \mathrm{sec}\end{array}$

From this time on, it is necessary to vent helium to maintain pressure. It is questionable that a pressure level of 4 ata can be maintained in the two phase system, at least until the relief system has been cooled. After $1 \mathrm{sec}$ a total of 24,000 joules have been added to the fluid of the magnet. At 4 ata and an internal energy of some 20 joules/gr, mass contained in the two phase system is of the order of 1,800 to $2,000 \mathrm{gr}$. In order to maintain 4 ata, we need to have vented some $600-800 \mathrm{gr}$ in $1 / 2 \mathrm{sec}$. The relief system cannot handle this until it has been cooled. For instance, a $3 / 4$ in. I.D. vent tube allows at $10^{\circ} \mathrm{K}$ at sonic velocity a flow rate of some $1,100 \mathrm{~g} / \mathrm{sec}$. Clearly, it is not sufficient to maintain 4 ata in the two phase vent system.

It appears that the pressure in the two phase system containing a large fraction of liquid will reach a high level before a sufficiently large rate of venting is achieved. The skin may fail. The situation is not much better at a point near the satellite refrigerator although the inventory is mostly gas. Table III provides the comparison between $P=1.2$ and $P=4.0$ ata without venting: 
T A B L E I I I

$\begin{array}{llll}\mathrm{P}=1.2 \text { ata } & \mathrm{P}=4.0 \text { ata } & \mathrm{P}=10 \text { ata } \\ \mathrm{M}=1,025 \mathrm{gr} & \mathrm{M}=1,025 & \mathrm{M}=1,025 \\ \mathrm{~V}_{\mathrm{S}}=24.4 \mathrm{cc} / \mathrm{gr} & \mathrm{V}_{\mathrm{S}}=24.4 & \mathrm{~V}_{\mathrm{S}}=24.4 \\ \mathrm{~T}=4.4^{\circ} \mathrm{K} & \mathrm{T}=7.1 & \mathrm{~T}=13.2 \\ \mathrm{I}=15,727 \mathrm{~J} & \mathrm{I}=29,725 & \mathrm{I}=48,900\end{array}$

Time elapsed is of the order of . $6 \mathrm{sec}$. Also, listed is a pressure level of 10 ata without venting. In order to reach this level, some 33,000 joules of heat need to be added. Time required is of the order of $1.4 \mathrm{sec}$. In order to maintain a constant pressure from this time on, fluid is ejected at a high rate. For instance, in $.1 \mathrm{sec} 2,400$ joules are added or roughiy 2.4 joules/gr. Internal energy is then $50.1 \mathrm{~J} / \mathrm{gr}, \mathrm{P}=10 \mathrm{ata}, \mathrm{T}=14.0^{\circ} \mathrm{K}$, and $\mathrm{V}_{\mathrm{S}}=26.4$. Fluid expelled is 78 grams. Rate is $780 \mathrm{~g} / \mathrm{sec}$. The vent system can handle this only after it has been cooled.

\section{Conclusions:}

1. A vacuum break into the insulating vacuum space will lead to a very high heat flux to at least the first and second magnets.

2. This heat flux will generate a very high pressure in the two phase liquid helium system and may lead to partial collapse of the wall separating single and two phase helium and/or rupture of the cryostat wall.

3. Heat leak to the nitrogen cooled shield will be relatively low and will not cause failure of the $\mathrm{N}_{2}$ circuits.

4. The two phase relief system should be evaluated carefully to make sure that cooldown of the vent piping in case of a massive fluid release does not lead to severe choking during the first second after the vacuum break occurs.

5. The collection header will behave in much the same way as postulated under Case I. 
RECOMMENDATIONS:

Since sonic velocity occurs in the break, rate of air flow may be limited by reducing the size of the pumpout lines. This appears to make sense, since conductance of the pump system is of little consequence when considering the impedance of the superinsulation in the insulating vacuum space.

The reduction of pump line size or the use of a restriction in the form of an orifice at the point where the pump line connects to the cryostat is the most effective means for reducing the effect of a massive vacuum break of the pumping systems. If necessary, the restriction may be made variable, in order to provide large pumping capability when the system is at ambient temperature. 
1. A Report on the Design of the Fermi National Accelerator Laboratory Superconducting Accelerator. Fermi National Accelerator Laboratory, May, 1979.

2. Nucleate and Film Pool Boiling Design Correlations for $\mathrm{O}_{2}, \mathrm{~N}_{2}, \mathrm{H}_{2}$, and He. International Advances Cryogenic Engineering, Vo1. 10, p. 325.

3. Chelton and Mann: Cryogenic Data Book UCRL 3421, p. 50 . 